\title{
The Causes and Solutions of Gender Inequality in the Workplace
}

\author{
Zhuolin $\mathrm{Zhu}^{1 *}$

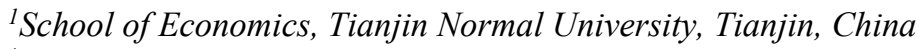 \\ *Corresponding author.Email: guanghua.ren@gecacademy.cn
}

\begin{abstract}
In this study, gender inequality is that people receive different treatment because of gender. In this present review, gender inequality is widespread in the workplace is found, including the prevalence of sexual harassment, the easier access to promotion opportunities for men than women, and the inconsistent retirement age for men and women, which can have negative consequences for employees, companies, and society. It means the gender inequality remains an important challenge in ensuring a safe and supportive working environment. In addition, the importance of studying gender inequality in the workplace is discussed, which is aimed at draw attention to gender inequality. Moreover, the main causes of these phenomena are discussed and explained, including sexism, the influence of patriarchy and traditional culture, and the lack of education. Finally, this paper also discusses how to solve these problems, including empowering women, using law and education to raise women's awareness of human dignity.
\end{abstract}

Keywords: Gender inequality, Workplace, Causes, Solutions

\section{INTRODUCTION}

\subsection{Definition of Gender Inequality}

Gender inequality is everywhere globally, and different studies have different definitions of gender inequality. Sen defined that gender inequality as not a homogeneous phenomenon; however, a series of different and interrelated issues [1]. Arora described that in their study, gender inequality is defined as inequality in women's access to education and health [2]. In this article, gender inequality is that people are treated unequally because of gender. People cannot enjoy the same rights and opportunities across all fields, including social, economic, and education.

\subsection{Performance of Gender Inequality in the Workplace}

In a temporary workplace, the public can find many manifestations of gender inequality. First of all, women are often sexually harassed in the workplace. Fitzgerald proposed that sexual harassment has been a fixed place of working life since women first sold labor on the market [3]. In addition, when women are sexually harassed as victims, they should have received more sympathy and care; however, they will be more criticized.
It is suggested that lack of attention to women themselves leads to harassment. However, Men are rarely harassed by colleagues or bosses. Second, men have more promotion opportunities than women. In addition, women have trouble breaking with senior management. Van thought gender inequality seemed like an unbeatable seven-headed dragon with many faces in an academic field [4]. In addition, Van also mentioned that the underrepresentation of females in senior academic positions persists at an international level [4]. This study thinks that women's abilities are not as good as the abilities of men, and when promoted, companies always think more about women. This is because people always think that women are better at housework and men are more suitable to work outside to earn money to support their families. Finally, the retirement-aged for men and women around the world is different. Men generally retire later than women. Pan studied that in the 172 countries and regions listed around the world, except for seven countries and regions, the retirement age is not marked, 7 in Asia, 8 in the Middle East and North Africa, 8 in sub-Saharan Africa, 24 in Eastern Europe and the former Soviet Union, 12 in Latin America and the Caribbean, 7 in Europe and North America and 1 in Oceania, with a total of 67 countries and regions with different retirement age for men and women and higher than men [5]. However, not all men want to retire later. 
They may want to retire early to relax. Women may also want to continue working as men. However, they are limited by the early retirement age. This is inequality both for men and women.

\subsection{Importance of Studying Gender Inequality in the workplace}

It is very important to study gender inequality in the workplace. First of all, it can make us aware of the dangers of gender inequality in the workplace. Molyneux thought that women's organizations are together because they have a common interest in defeating the power that limits their power [6]. For example, gender inequality in the workplace can affect work efficiency. In order to bring the public attention to and improve the status of women in the workplace. Second, it can let us understand that much more needs to be done to improve gender inequality in the workplace and create a good and harmonious working atmosphere. Instead of ignoring gender inequality in the workplace. However, pay more attention to this kind of problem. Thirdly, people that are not equal can be made aware of the unequal treatment they are subjected to. In addition, it can encourage more people that are unequal to stand up bravely and defend their legitimate rights. Khuzwayo proposed that South Africa has a history when women come together to raise awareness of issues affecting them and social change [7]. More importantly, people can prevent such behavior when they see others face inequality in the workplace. Finally, it is very helpful for us to understand gender inequality in society. This is because we can extend the workplace to society and life. Khuzwayo also proposed that although sometimes the movement towards women's resistance to gender inequality is not always successful, such as the Natal Women's Organization (NOW), organized around politics after 1994, alienating women who are not active in politics. However, many efforts have been made to bring women together to combat patriarchal injustices in all areas of South African society [7].

Studying this article will make us change our perception so that the public can work hard to achieve gender equality in the workplace and achieve gender equality in society. This can also prompt society to improve the law. In addition, the purpose of this study is to identify the causes of gender inequality and solutions.

\section{THE CAUSES OF GENDER INEQUALITY IN THE WORKPLACE}

\subsection{Sexism}

Sexism is a key reason for women's unequal treatment in the workplace. Cope studied that sexism plays a key role in explaining the persistence of the ceiling in women's workplaces and the slow promotion of women to senior positions in organizations of the world [8]. Women in the workplace are often subjected to more stringent requirements not necessary for work, such as women's age, height, and appearance. In addition, people always have a stereotype that women are less capable than men. In addition, when hiring women, they generally do not choose married and infertility females, and they will wonder whether women can balance their families and work, believing that women should deal with housework. This sexism leads to women's often more entry into low-level positions. This gender discrimination results in the unequal treatment of women in the workplace. World Economic Forum proposed that the percentage of Chinese men who are legislators, senior officials, and managers is $83.3 \%$, while $16.8 \%$ of Chinese women are legislators, senior officials, in addition, managers in 2021 [9]. Khuzwayo shows that in South Africa, $79.4 \%$ of senior managers are male, and only $18 \%$ are women. In addition, although $43 \%$ of women's professional qualifications and technical skills in their respective fields are comparable to those of men, this huge gap still exists [7]. In addition, society still has a prejudice against women in the temporary workplace that women are more suitable for the service industry. Naidu proposed that women entrepreneurs dominate the service industry, while entrepreneurs who are men dominate manufacturing. Female entrepreneurs are still underrepresented in manufacturing [10].

\subsection{Culture}

\subsubsection{Patriarchy in the society}

Edley and Wetherell studied patriarchy as an ideology passed down from generation to generation, believing that patriarchy belongs to men in the family [11]. Khuzwayo thought that the father's authority would never be questioned. It is exercised by men regarded as heads of households and women who submit to him [7]. This perception translates into a lower position for women in the labor force in the workplace. In addition, the role of leadership in society is generally regarded as men, not women. Khuzwayo studied that patriarchy is also reflected in the types of jobs allowed to men and women in the workplace and the ability of women to challenge gender oppression because they do not have a strong voice to challenge gender oppression [7]. In addition, because of patriarchy, women have no ownership and no rights in society. Therefore, in many parts of IGBO traditional culture, women do not own land. However, they work on land and manage most of their products [12].

\subsubsection{Traditional culture}

Oluwagbemi-Jacob and Uduma proposed that culture values male productivity more than female productivity, which meant that in this regard, society attaches 
importance to masculinity and rewards when gaining masculinity. Because women's characteristics do not have much weight on the social scale, they are not highly valued and rewarded when realized [12]. Zhang proposed that in Chinese traditional culture, women are soft inside, and men are strong outside. And in traditional Chinese values, this is a constant trend. In China's feudal society, the value of women was mainly reflected in the ability to produce a continuous flow of material and spiritual wealth for the clan. Raising children has become the only way for women to realize their ontological value. The feudal, patriarchal system used whether women could give birth to their own families as the first yardstick to measure the value of a woman and daughter, which was fixed by the state and legislation [13]. As a result, female employees often lose their promotions because they deem them to care for their families.

\subsection{Education}

Kane studied that traditionally, women are excluded from higher education, and in contemporary America, many people still believe that their limited participation in postgraduate courses and scientific and technological training hinders the achievement of gender equality [14]. The lack of education on gender equality leads to a lack of timely awareness of gender inequality. Even many women are not thinking they are suffering from gender inequality, which they think is normal. Kane also found that even women with higher education are still subordinate in the gender stratification system, although they may enter a more dominant economic position [14]. What is worse is that many girls cannot even receive an education. In this case, they do not even know what gender equality is and how to face gender inequality. In 2005 , only 59 out of 181 countries for which data are available (about one-third) achieved gender parity in gross enrolment in primary and secondary education (i.e., the average enrolment rate ranged from 0.97 to 1.03) [15]. Therefore, lack of education is caused by women having to work cheaper and more exploitative jobs in the workplace and not knowing how to use laws and rights to protect themselves when facing gender inequality.

\section{SOLUTIONS TO GENDER INEQUALITY IN THE WORKPLACE}

\subsection{Empower women}

Kim and Kay proposed that women's selfimprovement or "empowerment" at work has recently attracted the attention of the cultural community as a solution. In addition, the message of women's empowerment is also optimistic, focusing on women's future actions, not their past actions. They also suspect that more negative information criticizes women's past behavior as the cause of inequality [16]. The increase in women's rights means that they are more likely to hold higher positions in the workplace and are more willing to occupy higher positions. As Klugman, Kolb, and Morton said, huge inequalities in labor force participation and wage employment [17]. Therefore, when women are given more rights, women can have equal choices as men. For example, modify the recruitment process. When women and men have the same needs when recruiting, companies will not have more stringent requirements because they are women. Kim and Kay predict that this information will raise awareness of women's ability to improve gender equality in the workplace. Women's empowerment information directly shows that women can solve problems by overcoming internal obstacles [16]. In fact, for everyone, the inferiority complex that has existed for centuries is disappearing, while in others, the corresponding superiority complex is gradually emerging, which is rooted in socio-economic privilege, gender, and political status [18]. Empowerment of women improves the status of women, such as women's political participation. This allows women to participate more in core political positions such as governance and its institutions. Anyalebechi studied that in Nigerian, more women hold ministerial posts and parliamentary seats. For example, during the 2003-2007 government, 6 out of 34 ministers, 10 out of 35 special advisers, and 21 out of 360 representatives were women. During the election campaign, women are nominated as women leaders in grassroots politics of the community, local government, state, and national governments [18]. Therefore, only by improving women's rights can gender inequality be improved.

\subsection{Raise women's awareness of human dignity}

Anyalebechi quoted Pope John II that because women are increasingly aware of their human dignity, they will not tolerate being regarded as mere tools of reason. However, demand compliance with human rights in the family and public life [18]. Therefore, raising women's self-awareness of human dignity helps women enter the workplace to compete with men.

\subsubsection{Law}

Society can influence women's self-awareness by amending laws by raising their awareness of the most serious personality. Klugman, Kolb, and Morton thought that action could focus on removing legal and formal barriers to gainful work. The reform should focus on eliminating restrictions on women's labor and employment; removing unequal status clauses in family law, such as the head of the household clause; allowing and encouraging women to own and co-own land; enforcing fair inheritance laws; and applying the principle of non-discrimination to customary law. Most countries have made significant progress in fairer laws in recent decades. However, progress has been slow in some areas, especially in the Middle East, North Africa, and 
South Asia [17]. Therefore, by adjusting the law, women can be aware of the support of society for women. It allows women to be more confident and braver in the workplace. It can fundamentally change the psychological quality of women's inferiority.

\subsection{2.education}

Society can improve gender inequality and enhance women's awareness of self-worth by adjusting school education. Anyalebechi proposed that equality between men and women can only be achieved if all women are aware of their human dignity and no longer succumb to humble positions [18]. Therefore, the government could prepare the non-discriminatory textbook or curricula, promulgate regulations and policies, and carry out gender-sensitive teacher programs. In addition, schools should train teachers and carry out comprehensive sexuality education. This case can raise women's awareness of individual dignity by imperceptibly changing students' perceptions of gender inequality in education. When most women in society realize that they are important, not humble, and begin to say no to inequality, they can change gender inequality in society. Anyalebechi researched that woman must collectively make up their minds to change their situation forever because a tree can never build a forest. It lays the foundation for the future of the next generation [18]. And strengthening women's awareness of individual dignity can stop women from treating having children as the only way to realize their ontological value.

\section{CONCLUSION}

This paper analyzes many genders inequality in the workplace, such as the prevalence of sexual harassment, the more difficult access to promotion opportunities for women than men, and the inconsistent retirement ages for men and women. In addition, the main causes found in this study are sexism, patriarchy and traditional culture in the society, and the lack of education. Finally, some solutions, including empowering women and raising women's awareness of human dignity through legal, educational can help people deal with these phenomena. Overall, this work can provide well-rounded knowledge for the employees in the workplace and the government, incorporating the phenomenon, causes, and solutions of gender inequality.

\section{REFERENCES}

[1] Sen, A. (2001). The many faces of gender inequality. New republic, 35-39.

[2] Arora, R. U. (2012). Gender inequality, economic development, and globalization: A state level analysis of India. The Journal of Developing Areas, 147-164.
[3] Fitzgerald, L. F. (1993). Sexual harassment: Violence against women in the workplace. American Psychologist, 48(10), 1070.

[4] Van den Brink, M., \& Benschop, Y. (2012). Slaying the seven-headed dragon: The quest for gender change in academia. Gender, Work \& Organization, 19(1), 71-92.

[5] Jintang Pan. (2002). Retirement age for men and women in the world. Population and economy, 000(001), 75-80.

[6] Molyneux, M. (2001). Mobilisation without emancipation? Women's interests, the state and revolution in Nicaragua. In Women's movements in international perspective (pp. 38-59). Palgrave Macmillan, London.

[7] Khuzwayo, Z. (2016). Separate space: An approach to addressing gender inequality in the workplace. Journal of International Women's Studies, 17(4), 91-101.

[8] Cope, J. J. (2016). Culture, Sexism, and Legal Remedies: A Three Country Study of Gender Inequality at the Corporate Level (Doctoral dissertation).

[9] Global Gender Gap Report 2021: Insight Report. World Economic Forum. (n.d.). https://www.weforum.org/reports/global-gendergap-report-2021.

[10] Naidu, S., \& Chand, A. (2017). National culture, gender inequality and women's success in micro, small and medium enterprises. Social Indicators Research, 130(2), 647-664.

[11] Edley, N., \& Wetherell, M. (1995). Men in perspective. Pearson Education Limited.

[12] Oluwagbemi-Jacob, D., \& Uduma, C. E.. (2015). Gender equality, gender inequality, and gender complementarity: insights from igbo traditional culture. Philosophy research: English version, 005(005), 223-232.

[13] Yunyi Zhang. (1988) Sex discrimination in traditional Chinese culture. Sociological research, 2.

[14] Kane, E. W. (1995). Education and beliefs about gender inequality. Social Problems, 42(1), 74-90.

[15] Zeng, J., Pang, X., Zhang, L., Medina, A., \& Rozelle, S. (2014). Gender inequality in education in China: a meta-regression analysis. Contemporary Economic Policy, 32(2), 474-491.

[16] Kim, J. Y., Fitzsimons, G. M., \& Kay, A. C. (2018). Lean in messages increase attributions of women's 
responsibility for gender inequality. Journal of Personality and Social Psychology, 115(6), 974.

[17] Klugman, J., Kolb, H., \& Morton, M. (2014, July). Persistent gender inequality in the world of work. In The Fletcher Forum of World Affairs (pp. 133152). The Fletcher School of Law and Diplomacy.

[18] Anyalebechi, L. (2016). The issue of gender inequality in Nigeria. Journal of Policy and Development Studies, 289(3519), 1-9. 